\title{
Al Dios cristiano desde el ateísmo moderno ${ }^{1}$
}

\author{
Gerhard Ludwig Cardenal Müller \\ PREFECTO DE LA CONGREGACIÓN PARA LA DOCTRINA DE LA FE
}

Como decía Johann Wolfgang von Goethe, "La vida es demasiado corta para beber vino malo". Curioso proverbio este, que bien podría reflejar la concepción epicúrea del mundo y el nihilismo casi infantil por su terquedad, propios de las actuales élites posmodernas.

Frente a ello, la visión cristiana del mundo y del hombre es un verdadero canto a la vida y al optimismo. Es aquel optimismo que San Pablo expresa con entusiasmo en su Carta a los Romanos: "estad alegres en la esperanza, constantes en la tribulación, perseverantes en la oración, compartiendo las necesidades de los santos, practicando la hospitalidad" (Rom 12, 12-13).

Todos podemos constatar que la vida terrena es corta y conforme pasa el tiempo, la brevitas vitae se convierte en un desafío existencial. Pero esta es precisamente la cuestión: solo el beneficio del tiempo permite despertar del sueño de la ideología de la autorrealización, o lo que es lo mismo, de la visión del hombre que se apoya únicamente en sí mismo. Incluso podríamos decir: "la vida es demasiado corta para desperdiciarla con una mala filosofía". Gaudium et Spes dice al respecto: "ante la actual evolución del mundo, son cada día más numerosos los que se plantean o los que acometen con nueva penetración las cuestiones más fundamentales: ¿Qué es el hombre? ¿Cuál es el sentido del dolor, del mal, de la muerte, que, a pesar de tantos progresos hechos, subsisten todavía? ¿Qué valor tienen las victorias logradas a tan caro precio? ¿Qué puede dar el hombre a la sociedad? ¿Qué puede esperar de ella? ¿Qué hay después de esta vida temporal?" ( $\left.\mathrm{n}^{\circ} 10\right)$.

1 Nota del editor. Esta conferencia estaba prevista para el martes 10 de noviembre de 2015 en la Pontificia Universidad Católica de Chile, pero debido al atraso del vuelo que traía al Cardenal no llegó a pronunciarla. 
El ateísmo afirma que Dios no existe, lo cual no constituye en sí ninguna novedad. Acudamos, si no, a aquel salmo davídico que por tres mil años ha proclamado que "el necio dice en su corazón: que no hay Dios” (Ps. 14, 1). Las estadísticas más recientes demuestran un aumento vertiginoso de "conversos" al ateísmo: más del 10\% de la población mundial se declara atea. ¿Por qué más y más personas se vuelven ateas? ¿El ateísmo es realmente la postura más lógica, tal como afirman los ateos? ¿Por qué los libros del tipo El gen egoísta y el espejismo de Dios de Richard Dawkins o Dios no es bueno de Christopher Hitchens figuran en las listas de los más vendidos?

Benedicto XVI, en su carta al ateo Piergiorgio Odifreddi, ha afirmado que la teoría de la "mimética" de Richard Dawkins tan solo es una propuesta de "ciencia ficción". En sus obras, Dawkins explica que del mismo modo que los genes difunden la información biológica por procreación, así los "memis" difunden la información cultural por imitación. La ideas y las opiniones pasarían de mente a mente como "memis" invisibles. Aún más: Dawkins usa esta teoría a modo de crítica a la religión, pues según él, las creencias religiosas no son sino "virus" que atacan al hombre enfermo.

En cambio, el Dr. Michael Blume, famoso biólogo evolutivo y teólogo, se ha expresado recientemente en el sentido que "la afirmación de Benedicto XVI es plenamente correcta": ni los "memis" se han logrado definir a pesar de los numerosos intentos realizados, ni se puede afirmar que ningún estudio sostenible los haya verificado desde el punto de vista científico-empírico. Por otra parte, mientras que todos los "miméticos" han abandonado esta teoría ya en el 2010, hasta el momento presente Richard Dawkins aún no se ha pronunciado acerca del fracaso científico de esta propuesta (KATH.NET, Religionswissenschaftler bestätigt BenediktUrteil über Dawkins, 30 septiembre 2013).

¿Cómo explicar este dato? Hay que tener presente que la justificación que realiza el ateísmo moderno del proceso de descristianización que vive la civilización europea y norteamericana desde el siglo XVII, y su propuesta de un estilo de vida hedonista marcado por el lucro y el beneficio, se realiza bajo formas solo aparentemente científicas.

El llamado "neo-ateísmo" no ofrece, de hecho, ningún fundamento novedoso que no se pueda encontrar claramente formulado en David Hume y en todos los que han sido calificados y se califican como empi- 
ristas y materialistas. La única novedad que se ofrece al respecto desde el horizonte de la teoría evolucionista y neurofisiológica, solo se encuentra en los esfuerzos por ir más allá del enfoque propio de las ciencias naturales. Desde esta aproximación, la astrofísica, la biología y la investigación sobre el cerebro deberían llevar a una visión científica del mundo, supuestamente objetiva, sin tener presente que esta, al final, no permitiría al hombre ser persona, es decir, sujeto responsable de sus actos, ni tener una relación personal con Dios.

Hoy en día, la concepción pseudo-científica del mundo que promociona el neo-ateísmo, se exalta como un programa de opinión que hay que imponer a toda la humanidad. Llevada al extremo, esta teoría propugna que el que cree en la existencia de un Dios personal no debería tener derecho a existir ni en el mundo del pensamiento (por haber contraído el "virus divino", con lo que habría que ponerlo en cuarentena), ni tan siquiera en el físico (por ser un parásito social).

En este sentido, el carácter intolerante e inhumano del neo-ateísmo es aún más evidente si observamos el ateísmo político potenciado por el nacionalsocialismo en Alemania o el programa estalinista de extinción de la Iglesia ejecutado en la antigua Unión Soviética. Es una constatación que el llamado "ateísmo científico" ha tendido siempre a imponerse como cosmovisión y por sus características específicas, como programa político totalitario e inhumano.

$\mathrm{Al}$ inicio de la Era Moderna asistimos a la oposición entre empirismo y racionalismo en su intento por resolver el dualismo en favor de una de las dos vías de acceso a la realidad. ¿Puede el pensamiento apropiarse del mundo material? $\mathrm{O}$ a la inversa ¿la razón es una simple función del proceso evolutivo? El hombre, como sujeto pensante, ¿es solo parte de un momento de la diferenciación de la materia, sujeto a la ley de la selección natural como cualquier otro producto carente de sustancia o de una totalidad integral que lo comprende todo?

Robert Spaemann ha resumido bien el concepto de modernidad en sus repercusiones negativas sobre el hombre como persona, en tanto que ser con capacidades morales e intelectuales propias: "La visión científica del mundo substrae el yo y el tú de la corta vida del individuo, de su complejidad y significado, del ser representación única de lo incondicionado en pro de un desarrollo colectivo, el cual pasa a ser en sí mismo único portador verdadero de significado" (Gesammelte Reden und Au- 
fsätze I, 14). El enfoque de la modernidad tiene sus raíces en el empirismo de David Hume, según el cual "nunca vamos más allá de nosotros mismos" (cf. Gesammelte Reden und Aufsätze II, 9): hay que subrayar que esta visión reductivista no tiene en cuenta la capacidad evidente del intelecto de ir más allá de lo inmediato.

Los descubrimientos de la reciente investigación de tipo evolucionista y de la neurobiología se ocupan más bien poco de la condición subyacente del hombre, es decir, como ser dotado de una naturaleza corporal-espiritual y de una tendencia al conocimiento de la verdad y del bien, y por lo tanto, de una tendencia a la plena realización personal. Tales descubrimientos se limitan a considerar las condiciones materiales de la razón y de los actos de la voluntad del hombre, desde una interpretación pseudo-científica que se sobrepone a una filosofía basada en el materialismo monista. Dada su tendencia a convertirse en un monismo de tipo idealista, el verdadero proyecto de la modernidad, con su innegable valor humanizador, solo puede lograr su objetivo si supera la imposición del empirismo y sus derivados: el materialismo, el positivismo y el racionalismo.

Si queremos definir en plenitud al hombre, no podemos considerarlo como el mero objeto de sus propias investigaciones sobre la naturaleza, la historia, la cultura y la moral, pues siempre es aquel que se comprende a sí mismo en su propia mente. El hombre, como ser en el espacio y en el tiempo, no puede renunciar a la mediación sensible del contexto material y sociológico, los cuales sostienen las condiciones materiales de su existencia. Sin embargo, para garantizar tanto el proyecto de la libertad del individuo ante la colectividad, como la consciencia personal ante la ley puramente positiva y la dignidad inalienable de todo ser humano ante la instrumentalización de los intereses de grupo (clase, pueblo, capital, etc.), es indispensable una metafísica de la realidad y una antropología de la trascendencia del hombre que lo relacionen con la fuente de la creación.

Una metafísica del ser y del conocimiento de Dios, en el sentido propio de la teología filosófica, no tiene un mero interés histórico, sino que también son condición indispensable para que el proyecto de la modernidad no naufrague en la dialéctica propia del iluminismo. Por esta razón, el diálogo con la razón humana ha sido más importante que el diálogo con las religiones, tanto en los inicios del cristianismo como en el mo- 
mento presente, pues solo así se recupera el acceso completo a la realidad y, con ello, la posibilidad de elaborar una correcta teología natural.

No es necesario retornar a formas de metafísica ya caducas ante la propuesta que las ciencias naturales y la reflexión filosófica surgida en la modernidad hacen de la realidad mundana, ni para poder demostrar la racionalidad de nuestro enfoque ni menos aún de los contenidos de la Revelación sobrenatural de Dios en Jesucristo. En cambio, hay que partir de la experiencia del mundo real. La finalidad es lograr una autocomprensión refleja, en el sentido que el ser "espíritu" le da al hombre la posibilidad de hacer, y un conocimiento de Dios que no lo sea en sí mismo, sino en cuanto el mundo se relaciona con Él como origen y fin de todo el ser finito, incluido el hombre. El hombre se reconoce a sí mismo como persona únicamente a la luz de esta orientación trascendente. Cuando busca la verdad y tiende al bien, solo en Dios encuentra la paz.

Por lo tanto, el discurso sobre Dios no puede comenzar a partir de su "ser-en-sí", como si Dios se pudiera abstraer del mundo existente. Si la razón finita y creatural comienza siempre con la experiencia de que el mundo ya existe, la afirmación de que "Dios" está aquí permite significar el punto de proveniencia del ser y del espíritu, sin que sea una especie de objeto mundano que solo es conocido a modo de complemento. Como principio, el hombre está constitutivamente determinado como espíritu por la inevitable e indisponible referencia a Dios. A posteriori, el hombre debe tomar conciencia de este momento apriorístico y trascendente de su propia realización: solo así Dios aparece como el horizonte incircunscribible hacia el que nos movemos, y del que sabemos que derivamos en sentido absoluto, y no se convierte en un objetivo categorial. El espíritu se trasciende intencionalmente solo si está direccionado al infinito, solo si se reconoce constituido en su intencionalidad en este absoluto extramundano que es Dios. En última instancia explicativa, siempre está la realidad del Dios trascendente. En palabras de San Juan de la Cruz:

"Mil gracias derramando,

pasó por estos sotos con presura,

y yéndolos mirando, con sola su figura

vestidos los dejó de hermosura”. (Cántico Espiritual, 21-25)

El concepto "Dios" lo concebimos como la condición real de nuestro ser espiritual en el mundo y por lo tanto, también como condición de 
nuestra realidad finita. Mientras que Dios es su propia esencia a través de la posesión absoluta del ser, el mundo es realidad finita mediante la recepción del ser bajo forma de participación. El mundo participa en el ser de Dios por existir por voluntad de Dios, precisamente bajo forma finita. En cambio, Dios existe por sí mismo, en sí mismo, en virtud de sí mismo y por su propia realidad (cf. Ef 4, 6). Él es ipsum esse per se subsistens (Santo Tomás de Aquino, Summa theologiae, Ia, qu. 44, ar. 1).

Por ello, la naturaleza espiritual del hombre es el principio que hace finito y concreto el modo de su participación en el ser espiritual de Dios. Dios, en cambio, como Espíritu, está confiado directamente a sí mismo y puede disponer de sí mismo, de su ser espiritual. Ello significa que el espíritu forma parte constitutivamente de la referencia al origen del ser en general. Esta relación con Dios, incluso donde no llega a ser temática, constituye la existencia-en-sí, el presupuesto y la condición de lo que llamamos "ser personal".

La acción creadora de Dios es la perenne inserción del mundo en Dios y la realización de este a través de Dios. Por eso no existe ninguna contradicción entre la afirmación de la creación a través del Logos y el sostén que el Logos creador da a todas las cosas en el proceso evolutivo. En el hombre, la historia natural del ser penetra en la historia del espíritu y el hombre se concibe, por tanto, como recepción espiritual perfecta del ser real por parte de su esencia, en la que existe como persona, es decir, como ser-en-sí-mismo. La trascendencia de la persona creada para la participación de la realidad espiritual de Dios es posible, porque la creación es implícitamente auto-manifestación del ser y de la bondad de Dios. La creación del ser y del espíritu finito indica la apertura a un horizonte ilimitado para una explícita manifestación de Dios en su palabra. O lo que es lo mismo, el Creador del mundo, de la naturaleza y del hombre, va al encuentro del hombre en forma personal como cumplimiento de la auto-trascendencia, lo cual determina al espíritu creado, atraído por el Espíritu increado.

Fuera de lo creado, el acto único, atemporal e indivisible de la creación coincide con la actualidad de Dios. En la medida en que la actualidad infinita del ser se realiza de forma finita en lo creado, este no forma parte adecuadamente de la auto-iluminación divina. Pero en la medida en la que participa en el ser de Dios, es un medio creatural por el cual llegamos a conocer y amar a Dios. El conocimiento y el amor de Dios se 
manifiestan más profundamente en la participación creatural del autoconocimiento de Dios. Por eso, la realización creatural de un espíritu creado es un evento en el cual Dios mismo se da a conocer y amar. Así leemos en Romanos 1, 19-20: "Pues lo que de Dios se puede conocer, está en ellos manifiesto; Dios se lo manifestó. Porque lo invisible de Dios, desde la creación del mundo, se deja ver a la inteligencia a través de sus obras: su poder eterno y su divinidad, de forma que son inexcusables". Y en Hechos 17:26b-28a: "Él creó, de un solo principio, todo el linaje humano, para que habitase sobre toda la faz de la tierra fijando los tiempos determinados y los límites del lugar donde habían de habitar, con el fin de que buscasen la divinidad, para ver si a tientas la buscaban y la hallaban; por más que no se encuentra lejos de cada uno de nosotros; pues en él vivimos, nos movemos y existimos".

Concretamente, el hombre no existe en una especie de efectividad abstracta de la existencia, sino siempre en la realización concreta de esta en tanto que movimiento dinámico que tiende a completarse en el otro. Por ello llamamos "naturaleza" a la separación abstracta de la simple constitución (perfectio formae) respecto de su realización (operatio in perfectionem finis). Y en tanto que por tendencia, esta naturaleza se caracteriza por ser movimiento hacia la presencia de Dios y hacia el cumplimiento de la obra de este, hablamos de gracia. Si el hombre se aleja de Dios en su realización como libertad y espíritu, pierde la gracia y cae en la culpa (defectus gratiae): ante el pecado y la pérdida de Dios, la presencia salvífica permanente de Dios asume en el hombre el carácter de redención. Por ello, la realización creadora de Dios, por la cual la criatura existe, se revela como perdón y reconciliación. En su Redentor, el pecador encuentra al Creador.

En la creación, en su realización y en medio de las realidades creaturales, la presencia originaria de la gracia de Dios se hace de nuevo accesible bajo la forma de gracia de Jesucristo. En el Verbo eterno encarnado de Dios y en el Espíritu Santo de Dios infundido en los corazones, los justificados participan en la auto-revelación del Dios Uno y Trino, y así, en esta historia de salvación, se hacen realidad en el mundo. La actividad creadora de Dios en la Palabra que viene a nosotros en forma de redención, asume directamente en Jesús una realidad creatural. En Él, el pecador encuentra un medio creatural hecho totalmente por Dios, un medio que lo pone en contacto directo con el Creador cual Dios Redentor. Por 
ello, Jesús es el cumplimiento, la redención y el fundamento que recrea la naturaleza espiritual y su auto-trascendencia mediada creaturalmente para alcanzar la cercanía inmediata de Dios.

La trascendencia y la inmanencia de Dios están en relación inversamente proporcional. Solo porque Dios es absolutamente trascendente al mundo, puede ser de manera insuperable inmanente en el mundo. La conservación del mundo (creatio continua), no se debe concebir como una serie de actos creativos individuales y consecutivos, sino que consiste en la presencia atemporal e indivisible de la realización creadora dentro de la existencia y el movimiento del mundo. Dios es la causa prima que no anula las causae secundae creaturales de la forma, materia, causalidad, finalidad, sino que capacita para operar autónomamente en el modo que solo Él es capaz de hacer. La "intervención” de Dios en el mundo nunca puede significar una suspensión de la causalidad creatural. Sin embargo, Dios puede hacer que la causalidad creatural sea la causa instrumental de su específica voluntad salvífica hacia el hombre, el cual posee la libertad como forma concreta de su existencia. Por ello afirmamos que el hombre no tiene, sino que es, espíritu y libertad, aunque solo en forma finita.

Dado que el Dios trascendente mueve todas las cosas precisamente de acuerdo a la naturaleza creada de todo ser finito, también mueve al hombre de acuerdo a su naturaleza espiritual libre. La predestinación no elimina la libertad, sino que permite que la voluntad salvífica universal, aceptada desde la fe, sea el principio del auto-movimiento del espíritu hacia el fin prometido.

La relación entre la producción absoluta del hombre, su libertad operada por Dios y el auto-movimiento espiritual del hombre que constituye su libertad, se pueden expresar en estos términos: Dios no ejercita ninguna influencia fisicamente mensurable sobre la libertad creada, sino que va al encuentro de esta más bien como motivo (movens) de su acción. Cuando Dios viene a mí libremente en la palabra divina que lo manifiesta, se actualiza siempre como cumplimiento de mi libertad: Dios y su libertad permiten que el movimiento dinámico de la libertad de las criaturas se realice plenamente más allá de sus límites creaturales. En términos bíblicos, el hombre, de quien Dios se ha convertido en el motivo de su acción y de su auto-proyecto en el mundo, sabe que es una especie de "arcilla en las manos del Creador que lo modela". Como resultado, dice y confiesa que Dios obra en él el querer y el operar (cf. Fil 2, 13). 
Al mismo tiempo, no se ve desautorizado o privado de su libertad y personalidad. Por el contrario, se experimenta como capacitado para llevar a cabo su propia libertad. Mientras lo hace, sabe que solo gracias a la auto-donación de Dios, como cumplimiento de su libertad, está capacitado para actuar en orden a su propia finalidad. La realización se mueve hacia su fin solo por la presencia directa de la finalidad: la libertad está habilitada por la gracia para recibir, auto-realizándose, su aceptación por parte de Dios. En la gracia, Dios se revela como la fuente eterna de la libertad creada y su horizonte eterno bajo la forma de amor. La forma de la libertad humana, entonces, no se realiza en oposición a Dios, como lo ve el ateísmo, sino solo sobre la base de la libertad espiritual perfecta de Dios. Si Dios es exaltado, en consecuencia el hombre es exaltado. Por ello afirmamos que la salvación del hombre solo puede venir de Dios, el cual ofrece libremente su gracia a los hombres.

San Pablo escribe: "Pues habéis sido salvados por la gracia mediante la fe; y esto no viene de vosotros, sino que es un don de Dios; tampoco viene de las obras, para que nadie se gloríe. En efecto, hechura suya somos: creados en Cristo Jesús, en orden a las buenas obras que de antemano dispuso Dios que practicáramos" (Ef2, 8-10).

En este sentido, el Concilio Vaticano II enseña: "Cree la Iglesia que Cristo, muerto y resucitado por todos (cf. 2 Co 5, 15), da al hombre su luz y su fuerza por el Espíritu Santo a fin de que pueda responder a su máxima vocación y que no ha sido dado bajo el cielo a la humanidad otro nombre en el que sea necesario salvarse (cf. Hch 4, 12). Igualmente cree que la clave, el centro y el fin de toda la historia humana se halla en su Señor y Maestro" (Gaudium et Spes , 10).

Los que niegan el carácter metafísico de la teología natural y por lo tanto, la posibilidad del conocimiento de Dios a través de la Revelación, tienden a menudo a caer en las diversas formas de pesimismo cínico o nihilista. En cambio, la visión de la Iglesia se nutre de aquella plenitud que, por gracia de Jesucristo, todos hemos recibido (cf. Jn 1, 16). Si solamente Cristo es "la vid verdadera" $(J n 15,1)$ que ofrece el "vino bueno" (Jn 2, 10), necesario para la vida eterna, podemos concluir que solo la Iglesia es la verdadera promotora de la "modernidad", dado que solo la apertura a Dios, futuro del hombre, hace auténticamente posible para todos la esperanza que esta proclama. 
